\title{
DATA PELAYANAN OBSTETRI NEONATAL EMERGENSI KOMPREHENSIF (PONEK) DI RSUP PROF. DR. R. D. KANDOU PERIODE JANUARI 2014 - JUNI 2015
}

\author{
${ }^{1}$ Virginia R. Kaligis \\ ${ }^{2}$ Joice M. M. Sondakh \\ ${ }^{2}$ John J. E. Wantania
}

\author{
${ }^{1}$ Kandidat Skripsi Fakultas Kedokteran Universitas Sam Ratulangi Manado \\ ${ }^{2}$ Bagian Obstetri Ginekologi Fakultas Kedokteran Universitas Sam Ratulangi Manado \\ Email: virginiakaligis12179@yahoo.com
}

\begin{abstract}
PONEK is the form of the efforts to provide services for mothers and newborns in an integrated manner. The goal of PONEK is to reduce Maternal Mortality Rate (MMR) and Infant Mortality Rate (IMR). Obstacles that slow the decline of MMR and IMR in Indonesia are barriers to the provision and access to emergency obstetric and neonatal care. This was a descriptive retrospective study. The most frequent type of labor is the spontaneous labor with back of the head position. Implementation of IMD (early initiation of breast-feeding) has not reached $100 \%$ because it is still focused on normal labor. PMK (kangaroo mother care) services has reached 100\%, all BBLR (low birth weight) patients are treated with PMK. The most obstetric disease is premature labor. The most neonatal disease is caput succedaneum. MMR in 2014 was 298 deaths per 100.000 live births, until June 2015 increased 387 deaths per 100.000 live births. IMR for 2014 was 371 deaths per 1.000 live births, until June 2015 increased 453 deaths per 1.000 live births.
\end{abstract}

Keyword: PONEK

\begin{abstract}
Abstrak: PONEK merupakan bentuk upaya penyediaan pelayanan bagi ibu dan bayi baru lahir secara terpadu. Tujuan PONEK adalah menurunkan Angka Kematian Ibu (AKI) dan Angka Kematian Bayi (AKB). Kendala lambatnya penurunan AKI dan AKB di Indonesia adalah hambatan terhadap penyediaan dan akses pelayanan kegawatdaruratan obstetri dan neonatal. Penelitian ini menggunakan metode deskriptif retrospektif. Jenis persalinan tersering adalah spontan letak belakang kepala. Pelaksanaan IMD belum mencapai 100\% karena masih terfokus pada persalinan normal. Pelayanan PMK sudah mencapai $100 \%$ yaitu seluruh pasien BBLR yang dirawat dilakukan PMK. Penyakit kebidanan terbanyak adalah ancaman partus prematurus. Penyakit neonatal terbanyak adalah caput succedaneum. AKI tahun 2014 adalah 298 kematian per 100.000 kelahiran hidup, tahun 2015 sampai bulan Juni terjadi peningkatan 387 kematian per 100.000 kelahiran hidup. AKB selama tahun 2014 adalah 371 kematian per 1.000 kelahiran hidup, tahun 2015 sampai bulan Juni terjadi peningkatan 453 kematian per 1.000 kelahiran hidup.
\end{abstract}

Kata kunci: PONEK

Pelayanan Obstetri Neonatal Emergensi Komprehensif (PONEK) di Rumah Sakit merupakan bentuk upaya penyediaan pelayanan bagi ibu dan bayi baru lahir secara terpadu. Tujuan PONEK adalah menurunkan Angka Kematian Ibu (AKI) dan Angka Kematian Bayi (AKB). ${ }^{1}$ AKB dan AKI di Indonesia masih cukup tinggi dibandingkan dengan Negara ASEAN lainnya. Kendala lambatnya penurunan AKI dan AKB di Indonesia adalah hambatan terhadap penyediaan dan akses pelayanan kegawatdaruratan obstetri dan neonatal. $^{2}$ 
Penurunan AKI dan Angka Kematian Neonatal (AKN) merupakan dua dari delapan sasaran pembangunan nasional dalam meningkatkan status kesehatan masyarakat yang tertuang dalam Millennium Development Goals (MDGs) tahun 2015. ${ }^{3}$ Dalam mencapai target MDGs tersebut perlu dilakukan upaya terobosan yang efisien yaitu melalui program PONEK di Rumah Sakit. ${ }^{4}$ Jika pertolongan pada kasus kegawatdaruratan obstetrik dan neonatal dapat ditangani secara tepat, maka akan mempercepat penurunan AKI dan AKB. ${ }^{5}$

Dalam rangka menurunkan AKI dan AKB sesuai dengan Pedoman PONEK, tim PONEK RSUP Prof. Dr. R. D. Kandou Manado telah melaksanakan beberapa kegiatan. Kegiatan tersebut antara lain Inisiasi Menyusu Dini (IMD) dan Perawatan Metode Kanguru (PMK).

IMD merupakan pemberian kesempatan pada bayi untuk langsung menyusu dengan mencari puting ibunya sendiri setelah lahir. Dengan melakukan IMD bayi belajar beradaptasi dengan kelahirannya didunia, selain itu kedekatan antara ibu dan bayinya akan terbentuk dalam proses tersebut. ${ }^{6}$ Program IMD dapat menyelamatkan sekurang-kurangnya 30.000 bayi Indonesia yang meninggal pada satu jam kelahiran. Tindakan IMD juga akan membantu tercapainya tujuan MDGs nomor empat yaitu mengurangi

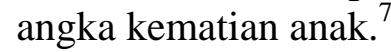

PMK adalah cara merawat bayi dalam keadaan telanjang (hanya memakai popok dan topi) diletakkan secara tegak/vertikal di dada antara kedua payudara ibu (ibu telanjang dada) kemudian diselimuti. ${ }^{8}$ Dalam metode ini, ibu atau ayah diidentikkan sebagai kanguru yang selalu mendekap bayinya. Sentuhan antara kulit ayah atau ibu dengan kulit bayinya seperti ini akan meningkatkan luasnya kontak kulit antara orang tua dan bayinya. ${ }^{9}$ Manfaat PMK dapat mencegah terjadinya hipotermi karena tubuh ibu dapat memberi kehangatan kepada bayinya secara terus menerus dengan cara kontak antara kulit ibu dengan kulit bayi. Selain itu manfaat PMK dapat meningkatkan ikatan kasih sayang antara ibu dan bayi, memudahkan bayi dalam memenuhi kebutuhan nutrisi, mencegah infeksi dan memperpendek masa rawat inap sehingga dapat mengurangi biaya perawatan. ${ }^{10}$

\section{METODE PENELITIAN}

Penelitian ini dilakukan menggunakan metode penelitian deskriptif retrospektif dengan mengumpulkan data sekunder. Penelitian ini dilaksanakan di Bagian Obstetri Ginekologi RSUP Prof. dr. R. D. Kandou Manado selama bulan Desember 2015 sampai Januari 2016.

\section{HASIL PENELITIAN}

Berdasarkan hasil pengumpulan data yang dilakukan pada bulan Desember 2015 Januari 2016 di Bagian Obstetri Ginekologi RSUP Prof. Dr. R. D. Kandou Manado diperoleh data PONEK periode Januari 2014 - Juni 2015 sebagai berikut:

Tabel 1. Distribusi Pelayanan Persalinan Januari 2014 - Juni 2015

\begin{tabular}{ccc}
\hline Jenis Persalinan & 2014 & 2015 \\
\hline Spontan LBK & 1926 & 561 \\
Spontan Bracht & 121 & 37 \\
Ekstraksi Vakum & 132 & 18 \\
Ekstraksi Forceps & 2 & 1 \\
Sectio Caesarea & 1166 & 416 \\
Total & 3347 & 1033 \\
\hline
\end{tabular}

Tabel 2. Distribusi Pelayanan IMD Januari 2014 - Juni 2015

\begin{tabular}{cccc}
\hline Tahun & $\begin{array}{c}\text { Jumlah } \\
\text { Persalinan } \\
\text { Spontan }\end{array}$ & IMD & (\%) \\
\hline 2014 & 1926 & 135 & 7 \\
2015 & 561 & 284 & 51 \\
\hline
\end{tabular}


Tabel 3. Distribusi PMK pada BBLR Januari 2014 - Juni 2015

\begin{tabular}{cc}
\hline Tahun & BBLR \\
\hline 2014 & 105 \\
2015 & 158 \\
\hline
\end{tabular}

Tabel 4a. Distribusi Penyakit Kebidanan Terbanyak Tahun 2014

\begin{tabular}{ccc}
\hline Jenis Penyakit & Jumlah & (\%) \\
\hline Ancaman Partus Prematurus & 116 & 6,67 \\
PEB & 53 & 3,04 \\
Anemia & 37 & 2,12 \\
Superimposed Eklampsi & 32 & 1,81 \\
Preeklampsi Ringan & 23 & 1,32 \\
Lain-lain & 1477 & 84,98 \\
Total & 1738 & $100 \%$ \\
\hline
\end{tabular}

Tabel 4b. Distribusi Penyakit Kebidanan Terbanyak Tahun 2015

\begin{tabular}{ccc}
\hline Jenis Penyakit & Jumlah & (\%) \\
\hline Ancaman Partus Prematurus & 61 & 4,36 \\
PEB & 51 & 3,64 \\
Anemia & 36 & 2,57 \\
Hipertensi Kronis & 10 & 0,71 \\
KPD & 9 & 0,64 \\
Lain-lain & 1232 & 88,06 \\
Total & 1399 & $100 \%$ \\
\hline
\end{tabular}

Tabel 5a. Distribusi Penyakit Neonatal Terbanyak Tahun 2014

\begin{tabular}{ccc}
\hline Jenis Penyakit & Jumlah & (\%) \\
\hline Caput Succedaneum & 247 & 8,81 \\
Suspek Sepsis & 196 & 6,99 \\
Pneumonia Neo & 106 & 3,78 \\
Hiperbilirubinemia & 102 & 3,64 \\
Febris & 40 & 1,43 \\
Lain-lain & 2113 & 75,35 \\
Total & 2804 & $100 \%$ \\
\hline
\end{tabular}

Tabel 5b. Distribusi Penyakit Neonatal Terbanyak Tahun 2015

\begin{tabular}{ccc}
\hline Jenis Penyakit & Jumlah & $\mathbf{( \% )}$ \\
\hline Caput Succedaneum & 119 & 10,5 \\
Suspek Sepsis & 97 & 8,55 \\
Pneumonia Neo & 70 & 6,17 \\
Hiperbilirubinemia & 47 & 4,14 \\
Diare Akut & 23 & 2,03 \\
Lain-lain & 777 & 68,57 \\
Total & 1133 & $100 \%$ \\
\hline
\end{tabular}

Tabel 6. Distribusi Jumlah Kematian Ibu Januari 2014 - Juni 2015

\begin{tabular}{ccc}
\hline Tahun & $\begin{array}{c}\text { Jumlah } \\
\text { Persalinan }\end{array}$ & $\begin{array}{c}\text { Kematian } \\
\text { Ibu }\end{array}$ \\
\hline 2014 & 3347 & 10 \\
2015 & 1033 & 4 \\
\hline
\end{tabular}

Tabel 7. Distribusi Kematian Bayi Januari 2014 - Juni 2015

\begin{tabular}{ccc}
\hline \multirow{2}{*}{ Tahun } & \multicolumn{2}{c}{ Kematian Bayi } \\
\cline { 2 - 3 } & $<$ 48 Jam & $>$ 48 Jam \\
\hline 2014 & 145 & 182 \\
2015 & 59 & 81 \\
\hline
\end{tabular}

\section{BAHASAN}

Berdasarkan data yang dikumpulkan, persalinan spontan merupakan jenis persalinan terbanyak. Pada Tabel 1, total persalinan tahun 2014 adalah 3347 persalinan dengan total persalinan spontan LBK sebanyak 1926 kasus. Total persalinan tahun 2015 sampai dengan bulan Juni adalah 1033 kasus dengan total persalinan spontan LBK sebanyak 561 kasus. Persalinan spontan Bracht pada tahun 2014 sebanyak 121 kasus dan pada tahun 2015 sampai bulan Juni sebanyak 37 kasus. Persalinan dengan ekstraksi vakum pada tahun 2014 sebanyak 132 kasus dan pada tahun 2015 sampai bulan Juni sebanyak 18 kasus. Persalinan dengan ekstraksi forceps merupakan jenis persalinan terjarang yaitu pada tahun 2014 hanya sebanyak 2 kasus dan pada tahun 2015 sampai bulan Juni sebanyak 1 kasus. 
Persalinan sectio caesarea pada tahun 2014 sebanyak 1166 kasus dan pada tahun 2015 sampai bulan Juni sebanyak 416 kasus.

Pelaksanaan IMD di RSUP Prof. dr. R. D. Kandou Manado masih terbatas pada bayi yang lahir spontan pervaginam. Berdasarkan Tabel 2, dari total 1926 persalinan spontan pada tahun 2014, hanya 135 diantaranya dilakukan pelayanan IMD dengan presentase sebesar 7\%. Sedangkan pada tahun 2015 bulan Januari-Juni terjadi peningkatan yaitu dari total 561 persalinan spontan, 284 diantaranya dilakukan pelayanan IMD dengan presentase sebesar 51\%. Cakupan IMD Nasional sebesar 34,5\%. ${ }^{11}$ Hal ini menunjukkan bahwa pelayanan IMD pada tahun 2015 di RSUP Prof dr. R. D. Kandou Manado cakupannya diatas angka nasional. Kendala utama yang ditemukan di lapangan yang berhubungan dengan pelaksanaan IMD antara lain, belum optimalnya komitmen penolong persalinan untuk selalu melakukan IMD pada bayi baru lahir. Faktor ibu bersalin juga berperan pada kegagalan IMD antara lain rendahnya pengetahuan ibu dan sikap ibu yang kurang mendukung IMD. Pada situasi tertentu bila bayi tidak bugar atau kondisi bayi setelah dilahirkan belum stabil, terkadang IMD tidak dapat dilakukan karena bayi harus segera mendapat perawatan lebih lanjut. ${ }^{12}$

PMK di RSUP Prof. Dr. R. D. Kandou Manado sudah berjalan dengan baik. Berdasarkan Tabel 3, jumlah pasien BBLR pada tahun 2014 adalah 105 kasus, dan pada tahun 2015 bulan Januari-Juni adalah 158 kasus. Seluruh pasien BBLR yang dirawat dilakukan PMK. Pelayanan PMK pada BBLR sudah dilakukan dengan tingkat minat ibu yang cukup, namun ada beberapa yang terkendala oleh ibu yang masih takut untuk menggendong bayinya. Ibu dan keluarga pasien perlu diberikan sosialisasi mengenai manfaat dan cara metode kanguru pada BBLR sebagai tindak lanjutnya.
Berdasarkan Tabel 4a dan Tabel 4b, penyakit kebidanan terbanyak adalah Ancaman Partus Prematurus dengan jumlah 116 kasus dari total 1738 pasien yang dirawat pada tahun 2014 dan 61 kasus dari total 1399 pasien yang dirawat pada tahun 2015. Penyakit kebidanan kedua terbanyak adalah Preeklampsia Berat (PEB) dengan jumlah 53 kasus pada tahun 2014 dan 51 kasus pada tahun 2015. Penyakit kebidanan ketiga terbanyak adalah Anemia dalam kehamilan dengan jumlah 37 kasus pada tahun 2014 dan 36 kasus pada tahun 2015. Penyakit kebidanan keempat terbanyak pada tahun 2014 berbeda dengan tahun 2015. Pada tahun 2014, penyakit kebidanan keempat terbanyak adalah Super Imposed Eklampsia dengan jumlah 32 kasus. Sedangkan pada tahun 2015, penyakit kebidanan keempat terbanyak adalah Hipertensi Kronis dengan jumlah 10 kasus. Penyakit kebidanan kelima terbanyak pada tahun 2014 berbeda dengan tahun 2015. Pada tahun 2014, penyakit kebidanan kelima terbanyak adalah Preeklampsia Ringan dengan jumlah 23 kasus. Sedangkan pada tahun 2015, penyakit kebidanan kelima terbanyak adalah Ketuban Pecah Dini (KPD) dengan jumlah 9 kasus.

Berdasarkan Tabel 5a dan Tabel $5 b$, penyakit neonatal terbanyak adalah Caput Succedaneum dengan jumlah 247 kasus dari total 2804 pasien yang dirawat pada tahun 2014 dan 119 kasus dari total 1133 pasien yang dirawat pada tahun 2015. Penyakit neonatal kedua terbanyak adalah Suspek Sepsis dengan jumlah 196 kasus pada tahun 2014 dan 97 kasus pada tahun 2015. Penyakit neonatal ketiga terbanyak adalah Pneumonia Neonatal dengan jumlah 106 kasus pada tahun 2014 dan 70 kasus pada tahun 2015. Penyakit neonatal keempat terbanyak adalah Hiperbilirubinemia dengan jumlah 102 kasus pada tahun 2014 dan 47 kasus pada tahun 2015. Penyakit neonatal kelima terbanyak pada tahun 2014 berbeda dengan tahun 2015. Pada tahun 2014, penyakit 
neonatal kelima terbanyak adalah Febris dengan jumlah 40 kasus. Sedangkan pada tahun 2015, penyakit neonatal terbanyak adalah Diare Akut dengan jumlah 23 kasus.

Berdasarkan Tabel 6, pada tahun 2014 dengan total 3347 persalinan didapat 10 kasus kematian ibu. Sedangkan pada tahun 2015 bulan Januari-Juni terjadi peningkatan yaitu dari total 1033 persalinan didapat 4 kasus kematian ibu. Angka kematian ibu tahun 2014 adalah 298 kematian per 100.000 kelahiran hidup. Sedangkan pada tahun 2015 sampai bulan Juni terjadi peningkatan 387 kematian per 100.000 kelahiran hidup.

Berdasarkan Tabel 7, jumlah kematian bayi selama tahun 2014 adalah 327 kematian dari total 880 pasien yang dirawat dengan 145 kasus dibawah 48 jam dan 182 kasus diatas 48 jam. Sedangkan pada tahun 2015 sampai bulan Juni terjadi peningkatan yaitu 140 kematian dari total 309 bayi yang dirawat dengan 59 kasus kematian dibawah 48 jam dan 81 kematian diatas 48 jam. Angka kematian bayi selama tahun 2014 adalah 371 kematian per 1.000 kelahiran hidup. Sedangkan pada tahun 2015 sampai bulan Juni terjadi peningkatan 453 kematian per 1.000 kelahiran hidup.

\section{SIMPULAN}

Tim PONEK RSUP Prof. Dr. R. D. Kandou Manado telah melaksanakan kegiatan-kegiatan dalam rangka menurunkan AKI dan AKB sesuai dengan Pedoman Penyelenggaraan PONEK di Rumah Sakit.

\section{DAFTAR PUSTAKA}

1. Direktorat Jenderal Bina Upaya Kesehatan Rujukan. Pedoman Rumah Sakit Pelayanan Obstetri Neonatal Emergensi Komprehensif (PONEK) 24 Jam. Jakarta: Departemen Kesehatan RI; 2012.

2. Permatasari E, Sidin I, Maidin A. Implementasi Kebijakan Pelayanan Obstetri Neonatal Emergensi
Komprehensif RSUP DR WAHIDIN SUDIROHUSODO Makassar Tahun 2013. Jurnal FKM UNHAS. 2013. h. 2.

3. Stalker P. Millennium Development Goal. Oktober 2008. h. 18-22. [diakses 9 Okt 2015]. Tersedia di: http://www.id.undp.org/

4. Wahyudi YP, Nurfaidah S, Irmawati I. Pengelolaan Rujukan Kedaruratan Maternal di Rumah Sakit dengan Pelayanan PONEK. Jurnal Kedokteran Brawijaya. 2014;28. h. 85.

5. Saleh F, Noor NB, Anggraeni $R$. Evaluasi Pelaksanaan Kebijakan PONEK di RSUD Haji Padjonga Daeng Ngalle Kabupaten Takalar. Jurnal FKM UNHAS.

6. Wulandari AS. Inisiasi Menyusu Dini untuk awali ASI Eksklusif. Jurnal Kedokteran Universitas Wijaya Kusuma Surabaya. h. 2-3.

7. Fithananti N. Faktor-faktor yang Berhubungan dengan Kinerja Bidan Puskesmas dalam Pelaksanaan Program ASI Eksklusif di Kota Semarang. Jurnal Kesehatan Masyarakat.2013;2. h. 1-10.

8. Triana A, dkk. Kegawatdaruratan Maternal dan Neonatal. Edisi pertama. Yogyakarta: Deepublish; 2015. h. 206.

9. Roesli U. Pedoman Pijat Bayi Prematur \& Bayi Usia 0-3 Bulan. Jakarta: Trubus Agriwidya; 2001. h. 24.

10. Silvia, Putri YR, Gusnila E. Pengaruh Perawatan Metode Kanguru terhadap Perubahan Berat Badan Bayi Lahir Rendah. Jurnal IPTEK Terapan. 2015. h. 2-3.

11. Kementerian Kesehatan RI. Infodatin: Situasi dan Analisis ASI Eksklusif. Jakarta Selatan. 2014.

12. Sejatiningsih S, Raksanagara AS. Program Inisiasi Menyusu Dini dalam rangka Menurunkan Angka Kematian Neonatal. Jurnal UNPAD. 2013. 